\title{
Offspring reaction norms shaped by parental environment: interaction between within- and trans-generational plasticity of inducible defenses
}

\author{
Emilien Luquet ${ }^{*}$ (I) and Juliette Tariel
}

\begin{abstract}
Background: Within-generational plasticity (WGP) and transgenerational plasticity (TGP) are mechanisms allowing rapid adaptive responses to fluctuating environments without genetic change. These forms of plasticity have often been viewed as independent processes. Recent evidence suggests that WGP is altered by the environmental conditions experienced by previous generations (i.e., TGP). In the context of inducible defenses, one of the most studied cases of plasticity, the WGP x TGP interaction has been poorly investigated.

Results: We provide evidence that TGP can alter the reaction norms of inducible defenses in a freshwater snail. The WGP $\times$ TGP interaction patterns are trait-specific and lead to decreased slope of reaction norms (behaviour and shell thickness). Offspring from induced parents showed a higher predator avoidance behaviour and a thicker shell than snails from non-induced parents in no predator-cue environment while they reached similar defenses in predator-cue environment. The WGP x TGP interaction further lead to a switch from a plastic towards a constitutive expression of defenses for shell dimensions (flat reaction norm).
\end{abstract}

Conclusions: WGP-alteration by TGP may shape the adaptive responses to environmental change and then has a substantial importance to understand the evolution of plasticity.

Keywords: Phenotypic plasticity, Transgenerational plasticity, Inducible defenses, Predator-prey interactions, Reaction norm, Physa acuta

\section{Background}

Phenotypic adaptation to fluctuating environments can occur through genetic evolution in response to natural selection over generations, or expression of traits within a generation in response to environmental cues (withingenerational phenotypic plasticity, WGP). Furthermore, non-genetic inheritance of phenotypic responses induced by a variety of biotic and abiotic stresses [1] occurs in many organisms [2]. Transgenerational plasticity (TGP) is a change in offspring phenotype that is cued by an environmental signal in the parental generation (and possibly the previous ancestors) without involving genetic

\footnotetext{
*Correspondence: emilien.luquet@univ-lyon1.fr

CNRS UMR 5023 Ecologie des Hydrosystèmes Naturels et Anthropisés,

Université Claude Bernard Lyon1, Université de Lyon, 43 Bd du 11 Novembre 1918, 69622 Villeurbanne cedex, France
}

change in offspring [3]. It can occur through environmental influence on maternal (or more generally, parental) effects, whereby the phenotype of an offspring depends on the phenotype of its parents, regardless of their genotype [4-7]. Mecanistically, it may be mediated by parental care (as often assumed for parental effects), or by any form of epigenetic inheritance not involving changes in the DNA sequence, including DNA methylation marks, histone protein modifications and small RNA molecules [8-10].

WGP and more recently TGP have been highlighted as mechanisms allowing rapid adaptive responses to environmental change $[3,5,11-13]$. Nevertheless, the acquisition of the adaptive phenotype via WGP may be delayed by the lack of offspring sensory organs that can detect reliable cues early in development, and by the 
time required for major developmental changes [14, 15]. TGP may allow overcoming such developmental constraints on the timing of plastic responses [16]. By producing plastically induced offspring, parents precondition them to a given environment, improving their survival early in life before they detect the environmental cues $[4,5,17]$. TGP may also allow acquisition of more accurate information about the average environment, by integration over a longer duration [18].

Thus, WGP and TGP both play a key role in adaptive responses to environmental changes. However, they are expected to evolve in slighlty different contexts [19]. WGP is selected when environments are spatially and/or temporally heterogeneous [20], costs of plasticity are low $[15,21]$ and cues reflect the state of the environment where selection operates on the phenotype [22-25]. In contrast, TGP is favoured when environmental (temporal) heterogeneity across generations and costs of obtaining information and responding are low, and when parental environment is a good proxy of offspring environment $[1,10,14,18,26,27]$. These forms of plasticity have often been viewed as separate processes, occuring independently from each other and thus contributing additively to the offspring phenotype (additive effect; Fig. 1a; Beaman et al. [28]). The majority of studies have only investigated how TGP can change mean trait values. Yet, recent evidence suggested that TGP can alter the WGP reaction norm (i.e., the full set of phenotypic responses to an environmental variable within a generation; Salinas et al. [29] for a review). This interaction between TGP and WGP can have substantial importance to understand the evolution of plasticity, because it can shape the adaptive strategies in response to environmental change. WGP $x$ TGP interaction may allow (i) to reach the adaptive phenotype faster and/or with a lower cost (Fig. 1b) or (ii) to change the adaptive phenotype according to the parental environment (change in direction of the offspring reaction norms; Fig. 1c). A recent theory suggests that the strongest transgenerational effects occur for traits that experience very strong selection and for which WGP is severely constrained [19]. Such a balance between WGP and TGP can shape the adaptive strategies in response to environmental change.

Inducible defenses are one of the most studied cases of WGP. A great variety of plants and animals produce ennemy-specific phenotypes by detecting enemy cues released in the environment $[3,30]$. There are numerous examples of morphological defenses induced by predator kairomones (cues) in animals. The most famous one is the expression of neckteeth in some Daphnia species, that is also the example used to define the terms of reaction norms [31]. Inducible defenses are an example of adaptive phenotypic plasticity improving fitness in presence of ennemies while avoiding potential costs associated with defense production when it is not needed [30]. Such evidence of phenotypic benefits and costs have been particularly demonstrated in predator-prey systems for inducible morphology, life-history and behaviour defenses in animals [32-37].

Parental exposure to predator cues can significantly alter the offspring phenotype (TGP), such as modifications in various life-history traits [38-40] or induction of defensive morphologies [16, 41, 42] or behaviour [43-46]. TGP of defenses may be highly advantageous and positively selected in nature $[3,12,16]$, and may thus be an important component of predator-prey interaction. Surprisingly, very few studies investigated the TGP on the offspring reaction norms of defensive traits themselves (e.g., Agrawal
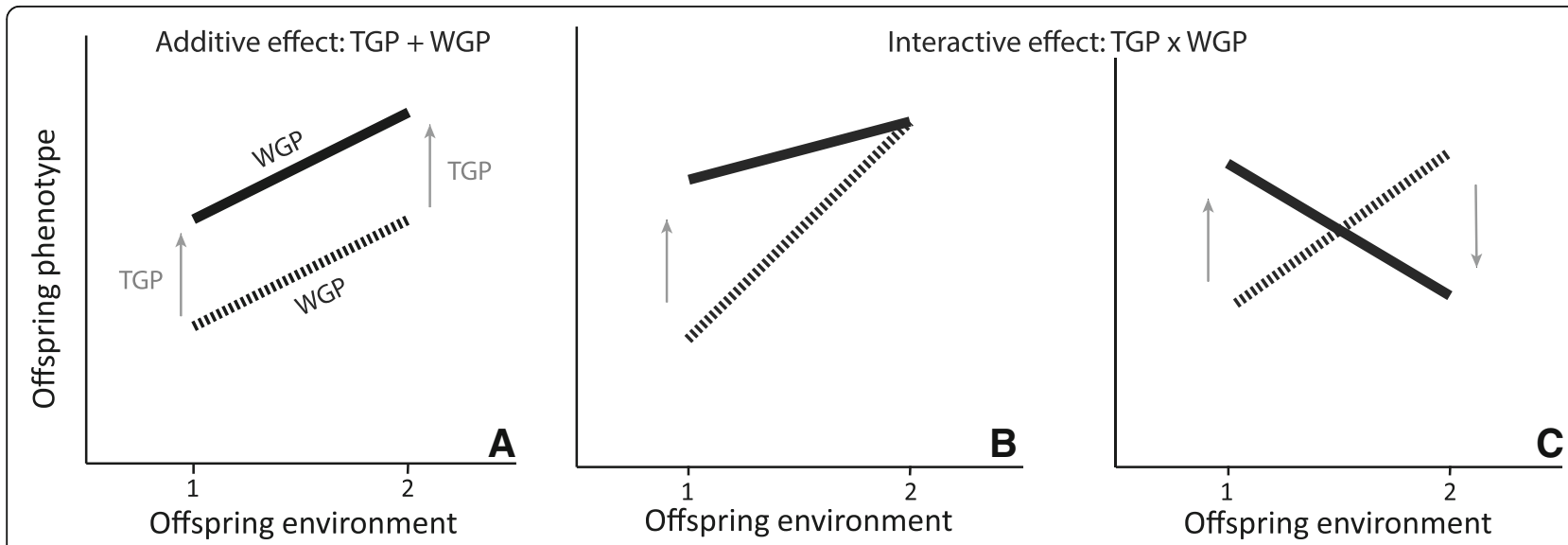

Fig. 1 Distinction between within-generational plasticity (WGP) and transgenerational plasticity (TGP), and their additive or interactive effects. Additive effect: (a) offspring phenotype is independently affected by offspring environment (WGP) and parental environment (TGP). Interactive effect: (b) the parental environment only alters the slope of the offspring reaction norm or (c) the parental environment alters the offspring reaction norm direction, producing an opposite response for a same offspring environment. 1 et 2 are two disctinct environments where the phenotype of the offspring is measured. The black and dashed lines represent offspring reaction norms for two different parental environments 
et al., [16]; Beaty et al., [42]). The pioneering study of Agrawal et al. [16] investigated the transmission of the anti-predator morph in Daphnia cucullata across several generations and showed that individuals with induced neckteeth produced offspring with a typical predatorinduced morph. However, there was no change in offspring reaction norms and their results thus demonstrated that WGP and TGP contributed additively to the offspring phenotype. Beaty et al. [42] found a similar additive contribution for one defense trait while other traits were exclusively affected by TGP or WGP in a freshwater snail. Changes in offspring reaction norms via TGP (interactive effect) are however well-known in other contexts $[28,29]$ but, to our knowledge, they have never been demonstrated for inducible defense traits.

In this study, we conducted an experimental twogeneration study to investigate how WGP and TGP can interact to shape the inducible defenses of the freshwater snail Physa acuta (behaviour and shell morphology) in response to predator cues. The hermaphroditic Physa gastropods have been used in numerous works studying inducible defenses (e.g., DeWitt [37]; DeWitt et al., [47]; Auld \& Relyea [48]; Gustafson et al., [49]; Auld \& Houser [50]; Beaty et al., [42]). Modifications of shell morphology and behaviour induced by predator cues are thus well-described (shell-crushing resistant: e.g., thicker shell, rotund shell shape and predator avoidance behaviour). In addition, the short generation time of this species allows to conduct an experiment across multiple generations. We compared the offspring reaction norms of inducible defenses (predator avoidance and shellcrushing resistant morphology) in response to parental and offspring environments (control and predator cues). We expected that parental environment can generate (i) an additive effect leading to an increase of maximal defenses in predator-cue offspring environment (higher proportion of predator avoidance, thicker shell, more rotund shell shape; Fig. 1a) and/or (ii) a WGP x TGP interaction, with a change in the slope (but not necessarily direction) of offspring reaction norms (Fig. 1b).

\section{Methods}

\section{Animal collection and experimental design}

Adult $P$. acuta snails were collected $(n=150)$ in March 2015 in a lentic backwater of the Rhône river $\left(45.80^{\circ} \mathrm{N}\right.$, $4.92^{\circ} \mathrm{E}$ ) in Lyon, France. Predators (fish and crayfish) are present in this natural environment. We pooled all snails overnight in a $10 \mathrm{~L}$-aquarium to ensure that offspring result from outcrossing ( $P$. acuta is a preferential outcrosser; Jarne et al. [51]). Then, we individually isolated all snails in $70 \mathrm{~mL}$ plastic boxes filled with reconstituted water $\left(2.4 \mathrm{~g} \mathrm{NaHCO}_{3}, 3 \mathrm{~g} \mathrm{CaSO}_{4}, 1.5 \mathrm{~g} \mathrm{MgSO}_{4}, 0.1 \mathrm{~g}\right.$ $\mathrm{KCl}$ to $25 \mathrm{~L}$ deionized water; $\mathrm{pH} 6.83$; [Ca2+] $=28 \mathrm{mg} /$ $\mathrm{L})$ in a $25{ }^{\circ} \mathrm{C}$ experimental room with $12 \mathrm{~h}$ light-dark photoperiod. After $24 \mathrm{~h}$, we haphazardly selected 15 of these wild-caught (G0) snails that had laid a first egg capsule each. These 15 egg capsules (hereafter called "families") developed until hatching ( 7 days) and constituted the parental generation (G1). Two days after hatching, we haphazardly sampled 12 siblings per family and split them into two environments: six snails remained in a no-predator environment while 6 others were moved in a predator-cue environment ( $n$ total $=180$ individuals). These G1 snails were reared in $70 \mathrm{~mL}$ plastic boxes with a constant density of six sibling/box. At 28-days old, they were isolated in the same type of plastic boxes. Boxes were closed to prevent snail escape. 7 G1 snails died during the experiment. At 35-days old, we generated the second generation. Predator cues were obtained by individually rearing crayfishes (Procambarus clarkii) in $4 \mathrm{~L}$ reconstituted water and feeding every 3 days with $\sim 200 \mathrm{mg}$ of $P$. acuta [48]. Twice a week, at each water renewal, the crayfish-conditioned water was used for the predator-cue treatment. Snails in the control treatment were always reared only in reconstituted water. Water and food (ad libitum, chopped and boiled lettuce) were renewed at the same frequency for all experimental snails.

To generate the offspring snail generation (G2), we formed six copulation groups per treatment. Each copulation group included 15 G1 adult snails (one individual per G1 family per treatment). Each group was placed for $24 \mathrm{~h}$ in a $5 \mathrm{~L}$ aquarium and thereafter individuals were isolated. After $24 \mathrm{~h}$, we haphazardly selected $17 \mathrm{G} 1$ snails from each treatment that had laid eggs (i.e., 17 families per parental treatment). We then followed the same protocol as previously to rear G2 snails in nopredator or predator-cue environments $(n$ total $=408$ ). 33 G2 snails died during the experiment. We measured the phenotypic traits at 49-days old. Individuals of the G2 generation consequently corresponded to one of the four life-history lineages: (i) control parents - > control offspring, (ii) control -> predator-cues, (iii) predatorcues $->$ control and (iv) predator-cues $->$ predator-cues (Additional file 1).

\section{Behavioural assay and morphology measurements}

To investigate TGP of anti-predator defenses, we estimated, on both G1 and G2, snails predator avoidance behaviour and measured six morphological traits (total weight, shell thickness, shell length, shell width, aperture length and aperture width) known to be influenced by predator cues and involded in adaptive anti-predator responses [37, 47, 48]. Snail behavioural response was recorded in their rearing boxes with predator cues present or absent according to the treatment, $24 \mathrm{~h}$ after a water change, 1 week before the morphology measurements. Predator avoidance behaviour was estimated by the proportion of snails crawling to the water surface or 
out of the water (called crawling-out behaviour hereafter). Snails were photographed and the software ImageJ (http://imagej.nih.gov/ij/) was used to measure the maximum lengths (shell length, shell width, aperture length and aperture width). The shell shape was assessed by calculating the shell length / shell width ratio. Shell thickness was measured with a numerical caliper at the nearest $0.01 \mathrm{~mm}$. Snails were weighed with an electronic scale at the nearest $0.001 \mathrm{mg}$.

\section{Statistical analyses}

The effect of predator cues on predator avoidance behaviour was analyzed using generalized linear mixed models assuming a binomial distribution (logit link function). The effect of predator cues on morphology was analyzed using linear mixed models with restricted maximum likelihood estimation and Kenward and Roger's approximation for degrees of freedom. Because all traits were strongly correlated with weight, we used analyses of covariance (ANCOVA) to control weight effect (log transformation) on the dependent variables, except for the shell length / shell width ratio (no significant correlation with weight). Interactions between the weight covariate and other fixed effects were removed when non-significant.

Parental (E1) and offspring (E2) environments (control or predator-cue) and their interaction were considered as fixed effects, and family was considered as a random intercept effect. When interactions with the weight covariate were significant (shell length and shell width), we splitted the weight covariate into two groups around the median (pre- and post- weight median) and then analyzed the effects of parental and offspring environments in each case. The results on aperture dimensions were all non-significant and were then not shown. The results on G1 generation are shown in supplementary material (Additional file 2). Generalized mixed models were done in R 3.2.1 ( $\mathrm{R}$ Core Team 2015) with the glmmPQL function (MASS package) and linear mixed models were done in JMP 10 (SAS Institute, NC).

\section{Results}

An interaction of Parental-by-Offspring environments affected crawling-out behaviour (GLMM, Parental env.: $\mathrm{t}_{35}$ $=2.928, p=0.006$, Offspring env.: $\mathrm{t}_{35}=5.5185, p<0.001$; Parental x Offspring env.: $\mathrm{t}_{35}=-2.177, p=0.036$; Fig. 2a)
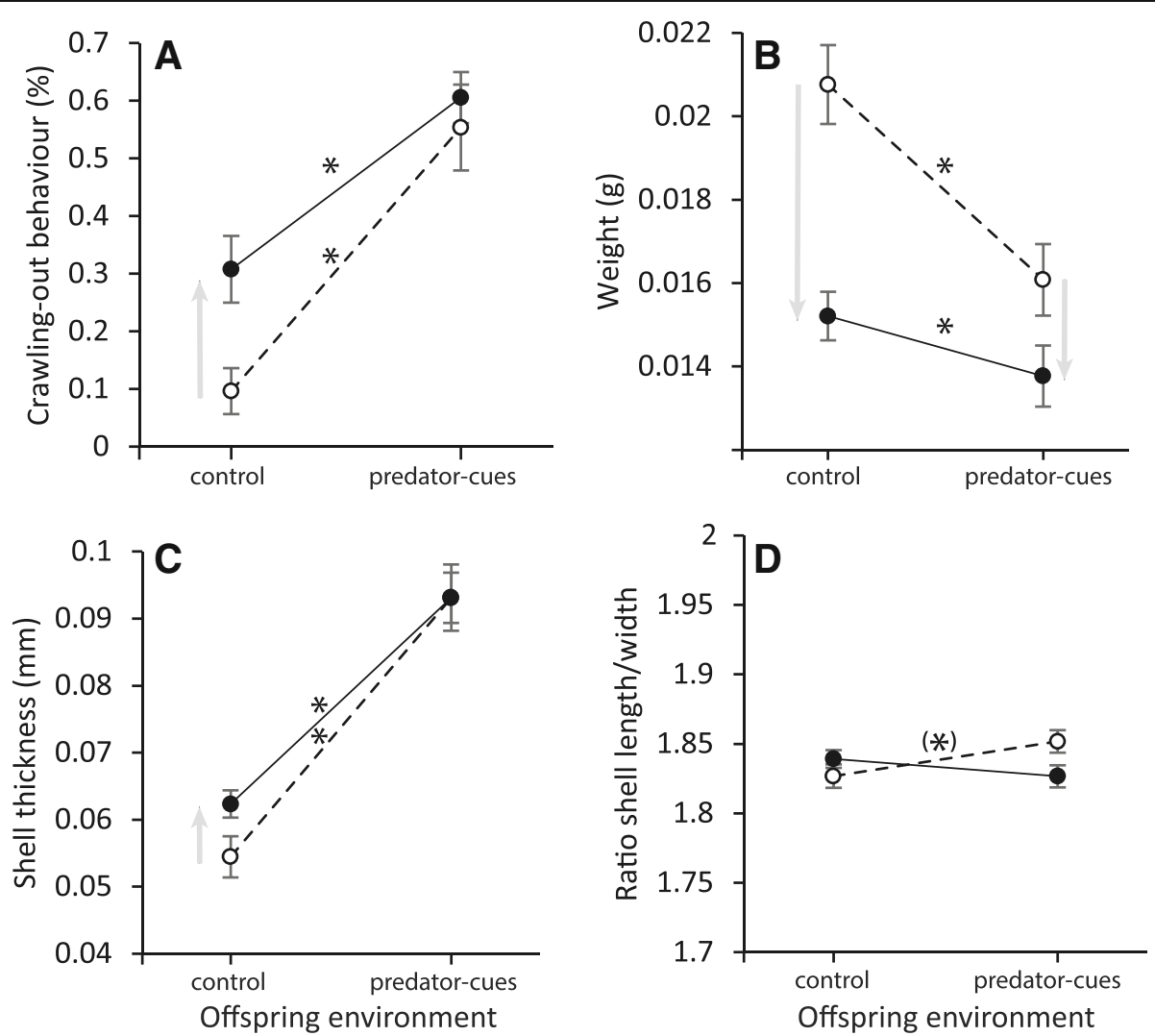

Fig. 2 Reaction norms of offspring phenotype (G2) according to parental (E1) and offspring (E2) environments for a crawling-out behaviour, b weight, c shell thickness and $\mathbf{d}$ ratio shell length / shell width. White circle and dashed line show reaction norms of offspring from control parental environment. Black circle and solid line show reaction norms of offspring from predator-cue parental environment. Significant TGP and WGP are showed by grey arrows and asterisk (*) respectively (see Table $1 \&$ Additional file 3) 
and shell thickness (Fig. 2c; Table 1), demonstrating that parental environment causes a shift in the slope of offspring reaction norms. Surprisingly, this interaction was sometimes antagonistic, such that exposing the parents to the predator cue reduces the response of their offspring to this cue. For instance, the increase in crawling-out behaviour and shell thickness in environment with predator cues was higher for offspring from control parental environment (45 and $71 \%$, respectively) than those from predator-cue parental environment (30 and $49 \%$, respectively). Regarding the direct effect of parental environment on offspring phenotype

Table 1 Results of linear mixed models analyses of (co)variance for the offspring generation (G2)

\begin{tabular}{|c|c|c|c|c|c|}
\hline \multirow[t]{6}{*}{ Weight } & & Estimates (SE) & Numdf, Dendf & $\mathrm{F}$ & $P$ \\
\hline & Parental env. (E1) & $-0.0020(0.0008)$ & $1,34.31$ & 6.95 & $0.0125^{*}$ \\
\hline & Offspring env. (E2) & $-0.0014(0.0004)$ & $1,336.73$ & 15.02 & $0.0001^{*}$ \\
\hline & $E 1 \times E 2$ & $0.0007(0.0004)$ & $1,336.73$ & 3.38 & 0.0667 \\
\hline & Random effect & Var & SE & Z & $P$ \\
\hline & Family & 0.0000169 & 0.00000536 & 3.12 & $0.0008^{*}$ \\
\hline \multirow[t]{7}{*}{ Shell thickness } & & Estimates (SE) & Numdf, Dendf & $\mathrm{F}$ & $P$ \\
\hline & Weight (W) & $0.0333(0.0034)$ & $1,340.63$ & 98.21 & $<0.0001^{*}$ \\
\hline & Parental env. (E1) & $0.0053(0.0023)$ & $1,37.49$ & 5.24 & $0.0278^{*}$ \\
\hline & Offspring env. (E2) & $0.0204(0.0017)$ & $1,343.66$ & 149.82 & $<0.0001^{*}$ \\
\hline & $E 1 \times E 2$ & $-0.0035(0.0016)$ & $1,341.77$ & 4.39 & $0.0368^{*}$ \\
\hline & Random effect & Var & SE & Z & $P$ \\
\hline & Family & 0.0000955 & 0.0000461 & 2.07 & $0.019^{*}$ \\
\hline \multirow[t]{10}{*}{ Shell length } & & Estimates (SE) & Numdf, Dendf & $\mathrm{F}$ & $P$ \\
\hline & Weight (W) & $1.7214(0.0206)$ & $1,352.56$ & 6999.59 & $<0.0001^{*}$ \\
\hline & Parental env. (E1) & $-0.0311(0.0161)$ & $1,37.23$ & 3.72 & 0.0613 \\
\hline & Offspring env. (E2) & $-0.0299(0.0104)$ & $1,341.09$ & 8.27 & $0.0043^{*}$ \\
\hline & $W \times E 1$ & $-0.0572(0.0206)$ & $1,352.56$ & 7.74 & $0.0057^{*}$ \\
\hline & $W \times E 2$ & $-0.0604(0.0194)$ & $1,360.90$ & 9.65 & $0.0020^{*}$ \\
\hline & $\mathrm{E} 1 \times \mathrm{E} 2$ & $0.0035(0.0104)$ & $1,341.09$ & 0.11 & 0.7347 \\
\hline & W $\times E 1 \times E 2$ & $0.0336(0.0194)$ & $1,360.90$ & 2.99 & 0.0845 \\
\hline & Random effect & Var & SE & Z & $P$ \\
\hline & Family & 0.00553 & 0.002214 & 2.50 & $0.0062^{*}$ \\
\hline \multirow[t]{9}{*}{ Shell width } & & Estimates (SE) & Numdf, Dendf & $\mathrm{F}$ & $P$ \\
\hline & Weight (W) & $0.9254(0.0121)$ & $1,347.72$ & 5867.74 & $<0.0001^{*}$ \\
\hline & Parental env. (E1) & $-0.0150(0.0090)$ & $1,34.82$ & 2.76 & 0.1054 \\
\hline & Offspring env. (E2) & $-0.0254(0.0059)$ & $1,340.22$ & 18.02 & $<0.0001^{*}$ \\
\hline & $W \times E 1$ & $0.0136(0.0061)$ & $1,341.69$ & 4.91 & $0.0274^{*}$ \\
\hline & $W \times E 2$ & $-0.0226(0.0120)$ & $1,349.57$ & 3.56 & 0.0600 \\
\hline & $E 1 \times E 2$ & $-0.0438(0.0114)$ & $1,362.95$ & 14.64 & $0.0002^{*}$ \\
\hline & Random effect & Var & SE & Z & $P$ \\
\hline & Family & 0.0016328 & 0.0007181 & 2.27 & $0.0114^{*}$ \\
\hline \multirow[t]{6}{*}{ Ratio shell length / width } & & Estimates (SE) & Numdf, Dendf & $\mathrm{F}$ & $P$ \\
\hline & Parental env. (E1) & $-0.0034(0.0058)$ & 1, 32.95 & 0.34 & 0.5635 \\
\hline & Offspring env. (E2) & $0.0024(0.0040)$ & $1,339.80$ & 0.35 & 0.5563 \\
\hline & $\mathrm{E} 1 \times \mathrm{E} 2$ & $-0.0087(0.0040)$ & 1, 339.80 & 4.66 & $0.0316^{*}$ \\
\hline & Random effect & Var & SE & Z & $P$ \\
\hline & Family & 0.0006571 & 0.0003111 & 2.11 & $0.0173^{*}$ \\
\hline
\end{tabular}


(TGP), offspring from predator-cue parental environment had a higher proportion of crawling-out behaviour and a thicker shell in control environment, but showed similar behaviour and thickness than offspring from control parental environment in predator cues environment (Fig. 2; Additional file 3 for contrast statistics). Parental and offspring environments additively affected weight (Fig. 2b; Table 1). Both parental and offspring environments reduced the weight in presence of predator-cues.

Both parental and offspring environment effects on shell length and shell width interacted with weight (Fig. 3; Table 1). The slice tests revealed that a significant Parental-by-Offspring environment interaction affected shell length and shell width above the weight median $\left(\mathrm{F}_{1,167.7}=4.49, p=0.0355\right.$ and $\mathrm{F}_{1,165.4}=8.95, p=0.0032$ respectively; Fig. 3; Additional file 4 ) but was not

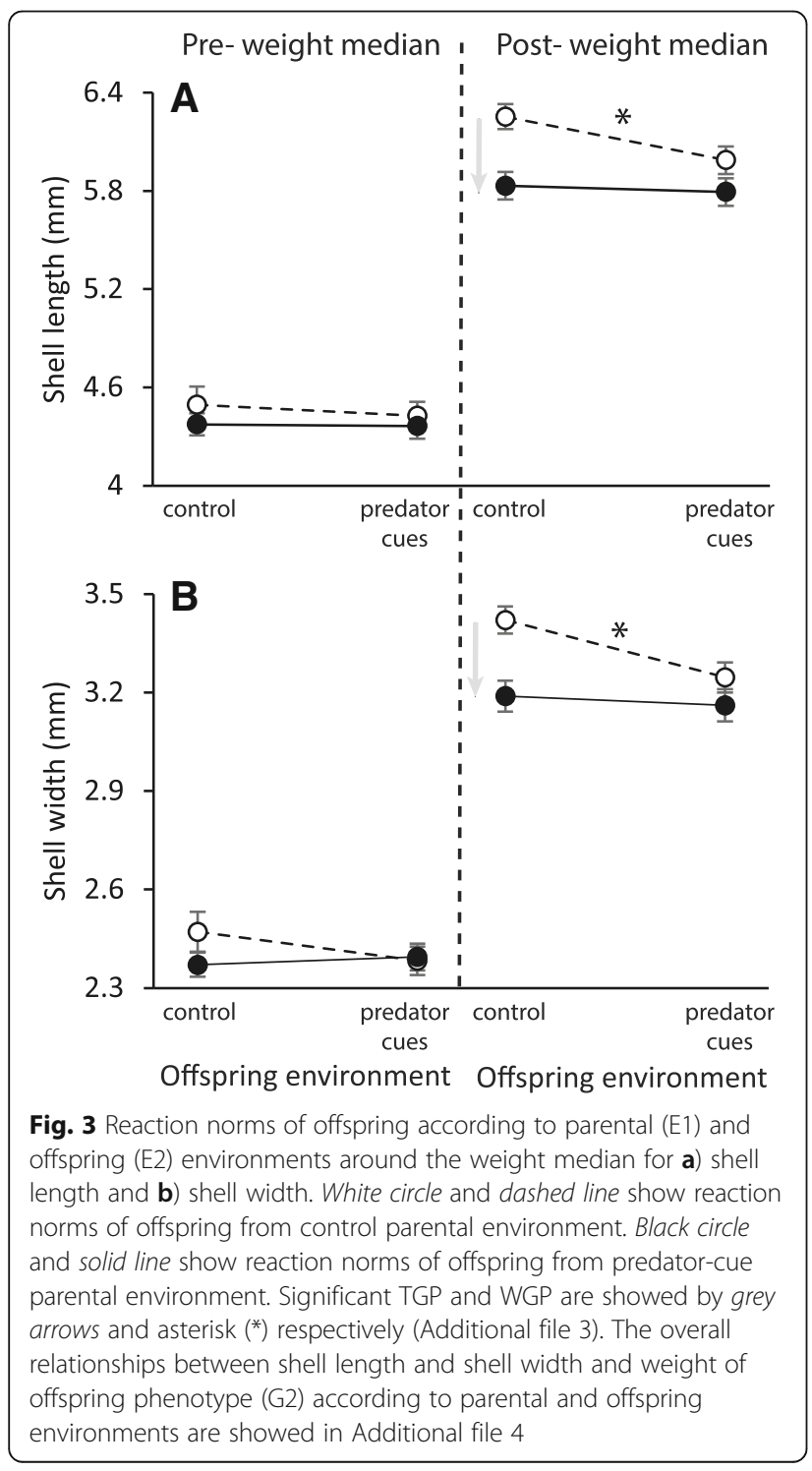

significant below the weight median (Fig. 3; Additional file 4). While the heaviest offspring from control parental environment showed a decrease in shell length and shell width with predator cues (Fig. 3), the heaviest offspring from predator-cue parental environment were globally shorter and narrower, and did not show a decrease in shell length and shell width with predator cues (flat reaction norms; Fig. 3; Additional file 3 for contrast statistics).

The shell length / width ratio was affected by a significant interaction between parental and offspring environments (Table 1). Offspring from control parental environment showed a marginal increase with predator cues while offspring from predator-cue parental environment were not affected by predator cues (Fig. 2d; Additional file 3 for contrast statistics). The family random effect was significant for every traits (Table 1).

\section{Discussion}

Our study showed TGP of defensive traits in P. acuta. Parents exposed to predator cues produced offspring with higher anti-predator defenses (predator avoidance behaviour and crush-resistant shell shape). More interestingly, we demonstrated that TGP can further alter the reaction norms of inducible defenses. Parental and offspring environments interacted to shape the reaction norms of inducible defenses in offspring. The most striking result was the switch from a plastic towards a constitutive expression of smaller shell dimensions (length and width) in offspring from induced parents. In other words plasticity in offspring was lost in response to the predatorcue environment of parents.

G1 snails in predator-cue environment exhibited antipredator defenses (Additional file 2) as observed in numerous studies [42, 48, 49, 52]. Such parental phenotypes induced by environment can be inherited in offspring. Some examples exist both in plants and animals $[53,54]$. TGP is predicted to be selected when the parental environment reliably predicts the offspring environment $[14,27,55]$. This is particularly expected in species with a short-generation time and a low dispersal like $P$. acuta because offspring are likely to live in the same environment than their parents [56]. Our study showed TGP for weight and all defensive traits of offspring G2 snails. Offspring from induced parents were lighter with significantly higher crawling-out behaviour, thicker shells and smaller shell dimensions in control environment. Although we did not measured fitness directly, several studies on gastropods showed that a crawling-out behaviour, a thicker shell, smaller shell dimensions and a rounded shape increase survival in crayfish-predation risk environment and are then considered as an adaptive response [37, 48]. Such TGP may be adaptive because it programs the defenses of offspring 
to the potential predation risk in the offspring environment, and importantly is in the same direction as WGP. However, the decrease in weight in offspring from induced parents may also be a transgenerational cost, and resulting from a higher investment of parents in defenses than in progeny. Predation risk is indeed known to affect the decision making of prey between predation avoidance and energy intake, and to increase the maternal stress acting on offspring development [50, 57, 58]. These results further suggest that offspring cannot totally overcome the parental environment effect because TGP was detected late in offspring development. The persistence of parental environment effect in offspring, even in the absence of predator cues, may lead to mismatched strategies for parents and offspring (i.e., parent-offspring conflicts) and thus to a maladptive TGP if the environment varies across generations [14].

Our study also revealed that TGP can alter the reaction norms of inducible defenses. The slope of offspring reaction norms for crawling-out behaviour, shell thickness and shell dimensions depended on the interaction between parental and offspring environments. Interestingly, offspring from both non-induced and induced parents reached overall a similar protection (crawlingout behaviour, shell thickness and shell dimensions) in predator-cue environment although reaction norms were different. This contrasts with the result on weight and a previous study on transgenerational induction of defense where Daphnia from induced parents increased the maximal helmet length in predator cue environment (i.e., additive effect; Agrawal et al. [16]). Our results rather suggest that the snail defensive traits may be constrained to maximal values in the experimental environment, which is probably not true for the weight because of ad libitum food. The anti-predator phenotype can be limited by the current environmental conditions because of production costs [15]. Such costs have already been demonstrated for induced-shell morphology defenses in Physa sp. [37]. Another possibility is that shell morphology was constrained by abiotic nutrients availability in environment. Bukowski and Auld (2014) [59] indeed demonstrated that calcium availability strongly affected the predator-induced shell morphology. Thus, constraints acting on inducible defenses can limit the evolution of additive effect (i.e., an increase of phenotypic maximal value) and generate WGP $\mathrm{x}$ TGP interactions.

Two different patterns of WGP $\mathrm{x}$ TGP interaction occured depending on the defensive traits. Some traits responded more strongly to the parental than to the offspring environment. Crawling-out behaviour and shell thickness increased in offspring predator-cue environment for both parental environments while shell dimensions (length and width) were only affected by offspring predator-cues for non-induced parental environment. Predator-induced TGP on crawling-out behaviour and shell thickness responses decreased the slope of the reaction norms. The parental environment induced intermediate defenses in offspring, which allows for offspring to keep a flexibility to react to the current environmental conditions, thus limiting the risk of maladaptive TGP. Surprisingly, TGP on shell dimensions led to constitutive defenses for offspring from induced parents (flat reaction norms). In this case, the maximum possible phenotypic response is already reached in response to parental environment (TGP), regardless of offspring environment, so no more WGP is required. Plasticity to the offspring environment is thus by-passed by the response to parental environment. The canalization of defenses in pre-conditioned offspring would immediately allow for the best protection against potential predation risk, and could be a costsaving strategy, but can lead to maladaptation if the environmental condition varies [3]. Such conflicting impacts of parental environment on reaction norms can result from a balance between WGP and TGP. A recent theoretical study showed that the largest effects of parental environment occured for traits with a low or severely constrained plasticity [19]. TGP would be favored for the most constrained plastic traits because it would be the only means of adaptation to a fluctuating environment. Crawling-out behaviour and shell thickness were the traits that exhibit the higher WGP (45 and $71 \%$ respectively) in our study (and in DeWitt et al. [47]; Auld \& Relyea [48]) compared to shell dimensions ( 4 and $5 \%$ for shell length and shell width respectively). The reaction norms for crawling-out behaviour and shell thickness were consistently the least affected by parental environment in our study. This is also consistent with Beaty et al. [42] study demonstrating that anti-predator behaviour was only affected by the current environment while crush resistance was only influenced by the parental one or shell size by both parental and offspring environments. The WGP of shell dimensions is probably more constrained by developmental processes than behaviour and shell thickness. High TGP on shell dimensions would allow to get a defensive shell morphology despite developmental constraints.

Some examples already showed that TGP can change the magnitude and even the direction of reaction norms (reviewed in Salinas et al. [29]). Here, we further demonstrated that TGP can involve a by-pass of WGP towards canalization of defenses in a subsequent offspring generation and without natural or artificial selection. In some cases, WGP can become reduced or lost, either from selection against costly developmental machinery underlying plasticity or because of relaxed selection when alternative environments 
are not frequently encountered [60]. Genetic assimilation is the complete loss of WGP, whereby an environmentally induced trait is selected to become constitutively expressed without the original environmental cue $[25,61,62]$. Our study suggests that TGP can favor the genetic assimilation of some defensive plastic traits when environment is stable. This result can have important implications for the evolution of inducible defenses. By influencing both phenotypic variance and offspring fitness, TGP can shape the course of genetic evolution in newly environmental conditions and accelerate the evolutionary response to predation risk $[28,55,60,63-65]$.

\section{Conclusions}

Consequently, predator-induced TGP responses on inducible defenses themselves may allow for a rapid adaptive response to predation risk and initiate evolutionary changes. The key distinction from the standard model of evolution from genetic variation is that evolutionary significant phenotypic novelty can arise from environmental and/or non-genetic alterations of the genotype-to-phenotype map [60]. Some theoretical studies modelled the rate of evolution with the possibility of such non-genetic inheritance $[1,26]$ but it is still unclear how WGP $\mathrm{x}$ TGP interaction evolves $[11,13]$. More theoretical and empirical studies on TGP and especially in the inducible defenses context are required to understand what determines which environments (past or current) shape the phenotype [42]. A dynamic view of defense induction according to parental environment would be further interesting to improve our understanding of adaptiveness of WGP $x$ TGP interaction (e.g., faster building of antipredator defense). Recently, Walsh et al. (Walsh et al. [66]) provided evidence that divergent ecological conditions in temporal variation of predation risk can select for WGP or TGP of life-history traits. However, they did not investigate how TGP alters WGP according to the ecological conditions. A next challenging question is to determine the genetic and nongenetic parts of inducible defense heritability [67]. The persistent effect of family on every measured traits indicated that both genetic variation and/or maternal effects occured. Furthermore, Dillon \& Jacquemin (2015) [68] showed a high heritability of shell morphological traits in Physa. An intensive knowledge is available on maternal effects and transmission of various factors in ovocytes $[4,5]$. However, environmental stressors like predators can potentially induce phenotypic change than span multiple generations [39]. Non-genetic inheritance of inducible defenses on more than two generations and underlying molecular mechanisms (e.g., epigenetic variation) deserve to be explored $[1,9,17]$.

\section{Additional files}

Additional file 1: Experimental design for evaluating WGP $\times$ TGP interaction. (DOC $60 \mathrm{~kb}$ )

Additional file 2: Results on G1 generation (DOC 64 kb)

Additional file 3: Contrast method on the estimates of models for shell thickness, shell length, shell width and ratio shell length / shell width in the G2 generation (see Table 1 for analyses of covariance). (DOC 49 kb)

Additional file 4: Relationships between A) shell length or B) shell width and weight of offspring phenotype (G2) according to parental (E1) and offspring (E2) environments (DOC $112 \mathrm{~kb}$ )

Additional file 5: Raw dataset used in this study. (XLSX $37 \mathrm{~kb}$ )

\section{Acknowledgments}

Thanks to E. Lebecq, J. Mornet and D. Reynaud for their help during field and lab work. We also thank S. Rouifed, S. Plénet, L.-M. Chevin, C. Téplitsky and two anonymous reviewers from the Peerage of Science platform for comments and advice that greatly improved the manuscript.

Funding

This work was supported by BQR-2015 grant to EL from the University Lyon 1

Availability of data and materials

Raw data are available in Additional file 5.

\section{Authors' contributions}

EL conceived and designed the study, EL and JT performed the experiment, analysed the data, drafted the initial version of the manuscript and contributed to later versions of the manuscript. Both authors read and approved the final manuscript.

\section{Competing interests}

The authors declare that they have no competing interests.

Consent for publication

Not applicable.

Ethics approval and consent to participate

Not applicable.

Received: 4 October 2016 Accepted: 7 October 2016

Published online: 12 October 2016

References

1. Bonduriansky R, Crean AJ, Day T. The implications of nongenetic inheritance for evolution in changing environments. Evol Appl. 2012;5:192-201.

2. Jablonka E, Raz G. Transgenerational epigenetic inheritance: prevalence, mechanisms, and implications for the study of heredity and evolution. Quaterly Rev Biol. 2009;84:131-76.

3. Holeski LM, Jander G, Agrawal AA. Transgenerational defense induction and epigenetic inheritance in plants. Trends Ecol Evol. 2012;27:618-26. Available from: http://dx.doi.org/10.1016/j.tree.2012.07.011.

4. Mousseau TA, Fox CW. The adaptive significance of maternal effects. Trends Ecol Evol. 1998:13:403-7

5. Sheriff MJ, Love OP. Determining the adaptive potential of maternal stress. Ecol Lett. 2013;16:271-80. Available from: http://www.ncbi.n/m.nih.gov/ pubmed/23205937.

6. Hadfield J. The quantitative genetic theory of parental effects. In: Smiseth PT, Kölliker M, Royle NJ, editors. Evol. Parent. Care. Oxford: Oxford University Press; 2012. p. 267-84.

7. Kirkpatrick M, Lande R. The evolution of maternal characters. Evolution. 1989;43:485-503.

8. Richards $\mathrm{CL}$, Bossdorf O, Pigliucci M. What Role Does Heritable Epigenetic Variation Play in Phenotypic Evolution? Bioscience. 2010;60:232-7.

9. Bossdorf O, Richards CL, Pigliucci M. Epigenetics for ecologists. Ecol Lett. 2008;11:106-15.

10. Bonduriansky R, Day T. Nongenetic Inheritance and Its Evolutionary Implications. Annu Rev Ecol Evol Syst. 2009;40:103-25. 
11. Salinas S, Munch SB. Thermal legacies: transgenerational effects of temperature on growth in a vertebrate. Ecol Lett [Internet]. 2012;15:159-63. Available from: http://doi.wiley.com/10.1111/j.1461-0248.2011.01721.x.

12. Herman JJ, Sultan SE. Adaptive Transgenerational Plasticity in Plants: Case Studies, Mechanisms, and Implications for Natural Populations. Front Plant Sci. 2011:2:1-10.

13. Shama LNS, Strobel A, Mark FC, Wegner KM. Transgenerational plasticity in marine sticklebacks: maternal effects mediate impacts of a warming ocean Funct Ecol. 2014;28:1482-93. Available from: http://doi.wiley.com/10.1111/ 1365-2435.12280.

14. Uller T. Developmental plasticity and the evolution of parental effects. Trends Ecol Evol. 2008;23:432-8.

15. Auld JR, Agrawal AA, Relyea RA. Re-evaluating the costs and limits of adaptive phenotypic plasticity. Proc R Soc B Biol Sci. 2010;277:503-11.

16. Agrawal AA, Laforsch $C$, Tollrian R. Transgenerational induction of defences in animals and plants. Nature. 1999;401:60-3

17. Jablonka E, Oborny B, Molnár I, Kisdi E, Hofbauer J, Czárán T. The adaptive advantage of phenotypic memory in changing environments. Philos Trans $R$ Soc Lond B Biol Sci. 1995;350:133-41. Available from: https://www.ncbi.nlm. nih.gov/pubmed/8577857.

18. Leimar O, McNamara JM. The Evolution of Transgenerational Integration of Information in Heterogeneous Environments. Am Nat. 2015;185:E55-69. Available from: https://www.ncbi.nlm.nih.gov/pubmed/25674697.

19. Kuijper B, Hoyle RB. When to rely on maternal effects and when on phenotypic plasticity? Evolution. 2015;69:950-68. Available from: http:// onlinelibrary.wiley.com/doi/10.1111/evo.12635/abstract.

20. West-Eberhard MJ. Developmental Plasticity and Evolution. New York: Oxford University Press; 2003.

21. DeWitt TJ, Sih A, Wilson DS. Costs and limits of phenotypic plasticity. Trends Ecol Evol. 1998:13:77-81.

22. Reed TE, Waples RS, Schindler DE, Hard JJ, Kinnison MT. Phenotypic plasticity and population viability: the importance of environmental predictability. Proc R Soc B Biol Sci. 2010;277:3391-400. Available from: http://rspb.royalsocietypublishing.org/content/277/1699/3391.short.

23. De Jong $\mathrm{G}$. Unpredictable selection in a structured population leads to genetic differenciation in evolved reaction norms. J Evol Biol. 1999;12:83951.

24. Tufto J. The evolution of plasticity and nonplastic spatial and temporal adaptations in the presence of imperfect environmental cues. Am Nat. 2000;156:121-30

25. Lande R. Adaptation to an extraordinary environment by evolution of phenotypic plasticity and genetic assimilation. J Evol Biol. 2009;22:1435-46

26. English S, Pen I, Shea N, Uller T. The information value of non-genetic inheritance in plants and animals. PLoS One. 2015;10:1-17.

27. Uller T, Nakagawa S, English S. Weak evidence for anticipatory parental effects in plants and animals. J Evol Biol. 2013;26:2161-70.

28. Beaman JE, White CR, Seebacher F. Evolution of plasticity: mechanistic link between development and reversible acclimation. Trends Ecol Evol. 2016;31: 237-49. Available from: http://linkinghub.elsevier.com/retrieve/pii/ S0169534716000185

29. Salinas S, Brown SC, Mangel M, Munch SB. Non-genetic inheritance and changing environments. Non-Genetic Inherit. 2013;1:38-50. Available from: http:// www.degruyter.com/view/j/ngi.2012.1.issue/ngi-2013-0005/ngi-2013-0005.xm

30. Tollrian R, Harvell CD. The Ecology and Evolution of Inducible Defenses. New Jersey: Princeton University Press; 1999.

31. Woltereck R. Weitere experimentelle Untersuchungen über Artveränderung, speziel über das Wesen quantitativer Artunterschiede bei Daphnien. Verhandlungen der Dtsch Zool Gesellschaft. 1909;19:110-73.

32. Van Buskirk J. The costs of an inducible defense in anuran larvae. Ecology. 2000:81:2813-21.

33. Teplitsky C, Plénet S, Joly P. Costs and limits of dosage response to predation risk: to what extent can tadpoles invest in anti-predator morphology? Oecologia. 2005;145:364-70

34. Hoverman JT, Relyea RA. Survival trade-offs associated with inducible defences in snails: the roles of multiple predators and developmental plasticity. Funct Ecol. 2009;23:1179-88.

35. Luquet $E$, Léna JP, David $P$, Joly $P$, Lengagne $T$, Perrin $N$, et al Consequences of genetic erosion on fitness and phenotypic plasticity in European tree frog populations (Hyla arborea). J Evol Biol. 2011;24:99-110.

36. Hammill E, Rogers A, Beckerman AP. Costs, benefits and the evolution of inducible defences: a case study with daphnia pulex. J Evol Biol. 2008;21:705-15.
37. DeWitt TJ. Costs and limits of phenotypic plasticity: tests with predatorinduced morphology and life history in a freshwater snail. J Evol Biol. 1998; 11:465-80.

38. Roche DP, McGhee KE, Bell AM. Maternal predator-exposure has lifelong consequences for offspring learning in threespined sticklebacks. Biol Lett. 2012:8:932-5. Available from: http://www.pubmedcentral.nih.gov/ articlerender.fcgi?artid=3497140\&tool=pmcentrez\&rendertype=abstract.

39. Walsh MR, Iv FC, Biles K, Munch SB, Walsh MR. Predator-induced phenotypic plasticity within- and across-generations: a challenge for theory? Proc R Soc B Biol Sci. 2015;282:20142205.

40. Coslovsky $\mathrm{M}$, Richner $\mathrm{H}$. Predation risk affects offspring growth via maternal effects. Funct Ecol. 2011;25:878-88.

41. Mondor EB, Rosenheim JA, Addicott JF. Predator-induced transgenerational phenotypic plasticity in the cotton aphid. Oecologia. 2005;142:104-8. Available from: http://link.springer.com/article/10.1007/s00442-004-1710-4.

42. Beaty LE, Wormington JD, Kensinger BJ, Bayley KN, Goeppner SR, Gustafson $K D$, et al. Shaped by the past, acting in the present: transgenerational plasticity of anti-predatory traits. Oikos. 2016;000:001-7. Available from: http://dx.doi.org/10.1111/oik.03114

43. Keiser CN, Mondor EB. Transgenerational behavioral plasticity in a parthenogenetic insect in response to increased predation risk. J Insect Behav. 2013;26:603-13. Available from: http://link.springer.com/article/10. 1007/s10905-013-9376-6

44. Storm JJ, Lima SL. Mothers forewarn offspring about predators: a transgenerational maternal effect on behavior. Am Nat. 2010;175:382-90. Available from: http://www.journals.uchicago.edu/doi/10.1086/650443.

45. McGhee KE, Pintor LM, Suhr EL, Bell AM. Maternal exposure to predation risk decreases offspring antipredator behaviour and survival in threespined stickleback. Funct Ecol. 2012;26:932-40.

46. Donelan SC, Trussel GC. Parental effects enhance risk tolerance and performance in offspring. Ecology. 2015;96:2049-55.

47. DeWitt TJ, Sih A, Hucko JA. Trait compensation and cospecialization in freshwater snail: size, shape and antipredator behaviour. Anim Behav. 1999; 58:397-407. Available from: http://dx.doi.org/10.1006/anbe.1999.1158.

48. Auld JR, Relyea RA. Adaptive plasticity in predator-induced defenses in a common freshwater snail: altered selection and mode of predation due to prey phenotype. Evol Ecol. 2011;25:189-202.

49. Gustafson KD, Kensinger BJ, Bolek MG, Luttbeg B. Distinct snail (Physa) morphotypes from different habitats converge in shell shape and size under common garden conditions. Evol Ecol Res. 2014;16:77-89.

50. Auld JR, Houser R. Age-dependent effects of predation risk on reproductive success in a freshwater snail. Evolution. 2015;69:2793-8.

51. Jarne P, Pointier JP, David P, Koene JM. Basommatophoran gastropods. Evol. Prim. Sex. characters Anim. Oxford: Oxford University Press; 2010. p. 173-96.

52. Auld JR, Relyea RA. Are there interactive effects of mate availability and predation risk on life history and defence in a simultaneous hermaphrodite? J Evol Biol. 2008:21:1371-8

53. Galloway LF, Etterson JR. Transgenerational plasticity is adaptive in the wild. Science. 2007:318:1134-6.

54. Walsh MR, Whittington D, Funkhouser C. Thermal Transgenerational Plasticity in Natural Populations of Daphnia. Integr Comp Biol. 2014;1-8. Available from: http://www.ncbi.nlm.nih.gov/pubmed/24948139

55. Badyaev AV, Uller T. Parental effects in ecology and evolution: mechanisms, processes and implications. Philos Trans R Soc Lond B Biol Sci. 2009:364:1169-77.

56. Uller T, English S, Pen I. When is incomplete epigenetic resetting in germ cells favoured by natural selection? Proc R Soc B Biol Sci. 2015;282. Available from: http://rspb.royalsocietypublishing.org/content/282/1811/20150682. long

57. Sheriff MJ, McMahon EK, Krebs CJ, Boonstra R. Predator-induced maternal stress and population demography in snowshoe hares: the more severe the risk, the longer the generational effect. J Zool. 2015;296:305-10. Available from: http://doi.wiley.com/10.1111/jzo.12249.

58. Auld JR. The effects of predation risk on mating system expression in a freshwater snail. Evolution. 2010;64:3476-94

59. Bukowski SJ, Auld JR. The effects of calcium in mediating the inducible morphological defenses of a freshwater snail. Physa acuta Aquat Ecol. 2014:48:85-90.

60. Schlichting CD, Wund MA. Phenotypic plasticity and epigenetic marking: an assessment of evidence for genetic accommodation. Evolution. 2014;68:656-72 
61. Schlichting CD, Pigliucci M, Murren CJ. Phenotypic plasticity and evolution by genetic assimilation. J Exp Biol. 2006;209:2362-7. Available from: http:// jeb.biologists.org/cgi/doi/10.1242/jeb.02070.

62. Crispo E. The baldwin effect and genetic assimilation: revisiting Two mechanisms of evolutionary change mediated by phenotypic plasticity. Evolution. 2007;61:2469-79. Available from: http://doi.wiley.com/10.1111/j. 1558-5646.2007.00203.x.

63. Badyaev AV. Evolutionary significance of phenotypic accommodation in novel environments: an empirical test of the Baldwin effect. Philos Trans R Soc B Biol Sci. 2009;364:1125-41. Available from: http://rstb. royalsocietypublishing.org/cgi/doi/10.1098/rstb.2008.0285.

64. Scoville AG, Pfrender ME. Phenotypic plasticity facilitates recurrent rapid adaptation to introduced predators. Proc Natl Acad Sci. 2010;107:4260-3. Available from: http://www.pnas.org/cgi/doi/10.1073/pnas.0912748107.

65. Badyaev AV. Stress-induced variation in evolution: from behavioural plasticity to genetic assimilation. Proc R Soc B Biol Sci. 2005;272:877-86. Available from: http://rspb.royalsocietypublishing.org/cgi/doi/10.1098/ rspb.2004.3045.

66. Walsh MR, Castoe T, Holmes J, Packer M, Biles K, Walsh M, et al. Local adaptation in transgenerational responses to predators. Proc R Soc B Biol Sci. 2016;283:20152271.

67. Danchin É, Charmantier A, Champagne FA, Mesoudi A, Pujol B, Blanchet S. Beyond DNA: integrating inclusive inheritance into an extended theory of evolution. Nat Rev Genet. 2011;12:475-86. Available from: http://dx.doi.org/ 10.1038/nrg3028.

68. Dillon RT, Jacquemin SJ. The heritability of shell morphometrics in the freshwater pulmonate gastropod physa. PLoS One. 2015;10:e0121962. Available from: http://dx.plos.org/10.1371/journal.pone.0121962.

\section{Submit your next manuscript to BioMed Central and we will help you at every step:}

- We accept pre-submission inquiries

- Our selector tool helps you to find the most relevant journal

- We provide round the clock customer support

- Convenient online submission

- Thorough peer review

- Inclusion in PubMed and all major indexing services

- Maximum visibility for your research

Submit your manuscript at www.biomedcentral.com/submit

C) Biomed Central 